\section{A statistical package in BASIC for small-system applications}

\author{
ALAN A. BAUMEISTER and WILLIAM E. MacLEAN \\ George Peabody College, Nashville, Tennessee 37203 \\ and \\ RICHARD DENI \\ Rider College, Lawrenceville, New Jersey 08648
}

This statistical package consists of 21 BASIC programs developed for use in teaching and research. They were written to conform to the procedural steps found in popular statistics handbooks (Bruning \& Kintz, 1977; Linton \& Gallo, 1975). The programs are selfinstructional, requiring keyboard data input and providing output at the user's terminal. They are well documented for easy alteration with regard to number of variables or number of scores.

The package was developed to serve the small-system user with standard BASIC, running either timesharing or real-time applications. The programs facilitate storage on a public device, and are written for easy adaptation to a variety of manufacturers' equipment. The package can easily supplement other statistical libraries specific to a given manufacturer (cf. Biderman, 1978)

Under timesharing, each program is brought in to the user's work area in the standard way. The individual programs in the package are listed below:

BDESC.BAS Distribution statistics including the mean, standard deviation, variance, standard error of the mean, and measure of kurtosis.

BTESTP.BAS $t$ test for a difference between a sample mean and a population mean.

BTESTI.BAS $t$ test for a difference between two independent samples.

BTESTR.BAS $t$ test for a difference between related samples, including calculation of a Pearson product-moment correlation coefficient.

BANOVS.BAS Simple analysis of variance for the completely randomized design (fixedeffects model).

B2FACT.BAS Two-factor analysis of variance for the completely randomized design (fixedeffects model).

BHO1.BAS Tukey test for a critical difference in making all comparisons between means.

This project was partially supported by NICHD Grant 00973 to the Institute on Mental Retardation and Intellectual Development, George Peabody College, Nashville, Tennessee 37203.
BHO2.BAS

BCO1.BAS

Scheffé test for a critical difference in making comparisons between means. Pearson product-moment correlation coefficient. The significance test for $r$ is done with a critical ratio $\mathrm{z}$ test if the number of pairs is 30 or larger a $t$ test is done if the number of pairs is smaller than 30 .

BSPEAR.BAS Spearman rank-order correlation (rho). Both the critical-ratio $z$ test and $t$ test are used, as in the case of the Pearson.

BKEND.BAS Kendall rank-order correlation (tau). The test of significance is based on the $z$ statistic.

BPOINT.BAS Point-biserial correlation for a continuous variable and a dichotomous variable. The test of significance is based on the $t$ test.

BRELO.BAS Reliability of measurement: Hoyt's procedure for the Kuder-Richardson coefficient.

BMANNU.BAS Mann-Whitney U-test for differences between independent samples. The significance test is based on a criticalration $\mathrm{z}$ value.

BPO3.BAS Wilcoxon test for differences between related samples.

BFRED.BAS Friedman test for differences among conditions in a within-subjects design.

BKRUSK.BAS Kruskal-Wallis test for differences among groups in a between-subjects design.

BANOVC.BAS Simple analysis of covariance with one treatment variable.

BCHISQ.BS Simple chi-square and the phi coefficient. Yates' correction for continuity is available. Complex chisquare and the contingency coefficient (C) are available.

BO1.BAS Tests for the significance of differences between two proportions.

BRAND.BAS Randomization program to generate lists of random integers with and without duplication.

Language and Computer. The package was written in DEC PDP-11/40 (RSTS/E) BASIC and runs on the DEC PDP-11/40. Modifications for use on any computer having standard BASIC would be minimal.

Availability. The source code for the package is available on magnetic tape (800 bpi, any word size, ASCII) or paper tape. Costs may be obtained from Richard Deni, Psychology Department, Rider College, Lawrenceville, New Jersey 08648. 


\section{REFERENCES}

Biderman, M. D. A statistical package for the HewlettPackard 2000/Access. Behavior Research Methods \& Instrumentation, 1978, 10, 417-418.

Bruning, J. L., \& Kintz, B. L. Computational handbook of statistics. Glenview, Ill: Scott Foresman, 1977.

LinTon, M., \& Gallo, P. S., JR. The practical statistician: Simplified handbook of statistics. Monterey, Calif: Brooks/Cole, 1975.

(Accepted for publication December 28, 1978.) 